\title{
A Flexible Online Apparatus for Projectile Launch Experiments
}

\author{
http://dx.doi.org/10.3991/ijoe.v9iS1.2289 \\ Carlos Paiva, Pedro Nogueira, Gustavo Alves, Arcelina Marques, Pedro Guimarães, Rubem Couto \\ 2 Polytechnic of Porto, Porto, Portugal
}

\begin{abstract}
In order to provide a more flexible learning environment in physics, the developed projectile launch apparatus enables students to determine the acceleration of gravity and the dependence of a set of parameters in the projectile movement. This apparatus is remotely operated and accessed via web, by first scheduling an access time slot. This machine has a number of configuration parameters that support different learning scenarios with different complexities.
\end{abstract}

Index Terms-Remote Experiment, projectile launch.

\section{INTRODUCTION}

Distance education has been in use for several years at the Polytechnic of Porto - School of Engineering (ISEP), but the application of remote laboratories in physics was exclusively being used in the electric and electronic fields. For that purpose, VISIR [1, 2] and Remote ElectLab [3] supported remote experiments in electronics. The need for a similar approach supporting other experiments in Physics has led us to develop a machine able to perform projectile launch experiments remotely. This type of apparatus, supporting different complexity levels on the projectile movement characterization, can be used to address several topics on a typical physics curriculum, under different learning scenarios.

A similar approach with a free body fall apparatus to achieve gravity acceleration determination has been developed by Martin Connors and described in [4].

\section{APPARATUS LAYOUT}

This apparatus is a self-contained box that requires a power plug and an Ethernet connection. The box has an internal web server accessible through a SCORMcompliant scheduler. This server also enables a local mode for use in exhibitions and demonstrations. The apparatus is shown in Fig. 1 and is divided in four sub-assemblies:

\section{A. Ball Selector}

Selects one out of three balls with diameters ranging from $14 \mathrm{~mm}$ to $18 \mathrm{~mm}$, allowing the study of mass (non-) influence on projectile motion.

\section{B. Main Elevator}

Executes three operations in the process. Firstly, it loads the ball by moving to its lower limit loading position. Then it lifts-up the ball to a position leveled with the ramp. If the ramp is on place it will move up for a few millimeters to mechanically launch the ball to a zone where an electromagnet placed on the ramp will collect it.

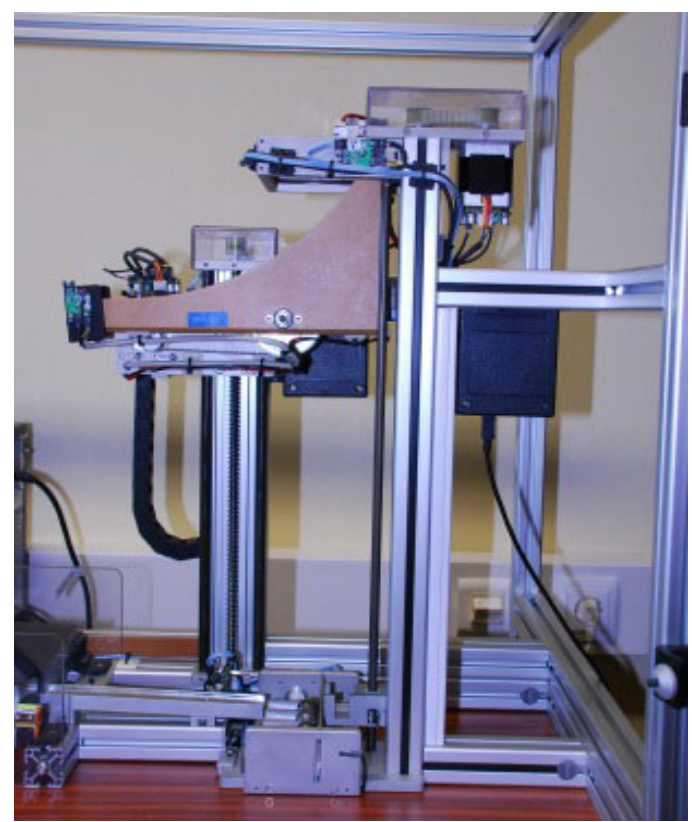

Figure 1. Apparatus side view

\section{Ramp Elevator}

Ramp Elevator has two main purposes: user setup angle and user setup height. The ramp angle can range from $-20^{\circ}$ to $+20^{\circ}$. The launch height can be set up to $380 \mathrm{~mm}$ above touch down plane. Switching off the electromagnet triggers the ball movement down the ramp.

\section{Ball Collector (landing zone)}

Works by gravity and its main purpose is to collect the launched ball back to the ball selector. This assembly also contains the projectile horizontal range measuring system. This is an optical system based on a reflective infrared light barrier. The impact point measurement is obtained by interrupting a set of photo-detectors, $2 \mathrm{~mm}$ apart.

\section{WEB INTERFACE}

The web interface (Fig. 2) allows users to setup their experiment and receive the experimental data. It also provides the user with a live video stream of the whole process, captured by a webcam. Together with the experimental data, a photo taken at the moment the ball touches the landing zone is also sent via the user interface. The purpose of this photo is to allow users to make the actual measurement of the maximum horizontal displacement in order to compute the projectile range. All data is available for inspection via the user interface. 


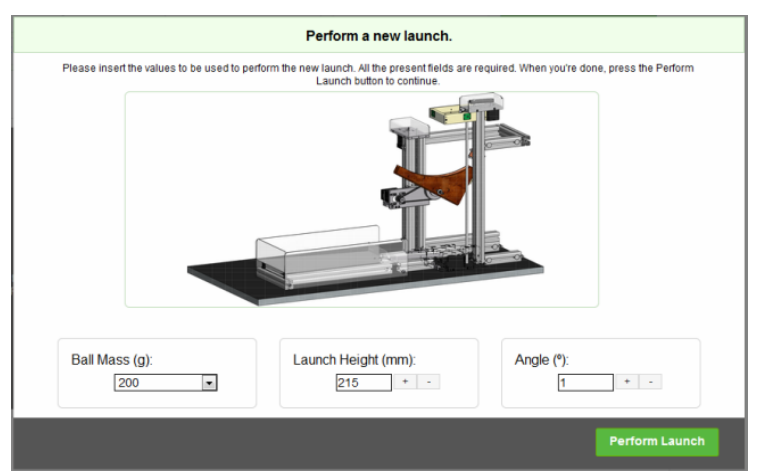

Figure 2. Web User Interface

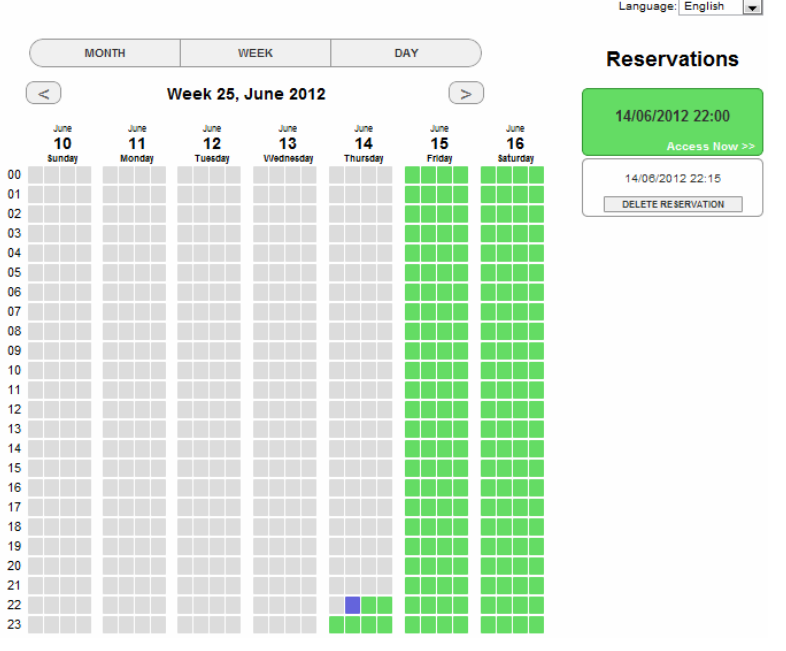

Figure 3. Scheduler Interface

\section{EXPERIMENT FLOW}

The experiment is accessed through a scheduler shown in Fig. 3 via web. The student reserves a predefined time slot to execute the pretended experiments. During this period, he may submit data (using web services) to the machine as many times as possible.

For each trial, in the first interface window (Fig.2) students are requested to specify the experiment variables. These variables will be reflected in the machine setup. Upon reception of request, the machine validates all incoming data, verifies the availability of resources, checks for errors and, if everything is correct, returns a flag signaling "Experiment in progress". In case an error is found, the error code is returned.

As stated before, the machine process starts by selecting the desired ball at "Ball Selector" (Fig. 1). After selection, the main elevator goes down in order to load the selected ball into the elevator. This main elevator will raise the ball up to the ramp load position at its top most location and wait for ramp to signaling to be ready to accept the ball transfer.

When the ramp is ready, an electromagnet is turned ON to grab the ball. At this moment, the main elevator will push the ball and starts its trip down to be ready to receive next trial ball. The ramp with the ball coupled to the electromagnet turns to the desired angle and starts moving to reach the user selected height. After a small delay necessary to stabilize the mechanical vibration, the electromagnet is switched off and the projectile launch starts. The ball rolls down the ramp and will hit the landing zone in the ball collector where a sensor by detecting this event, computes the ball travel time. Also, the infrared light barrier detects the impact point and determines the maximum horizontal displacement, which in turn, will be used to compute the projectile range of motion. Finally, the ball collector will return it by gravity to the ball selector, therefore reaching the stop point necessary to the start of a new trial.

After completion of the machine cycle, experimental data returns to the web server and sent to the user.

\section{REsults AND VALidATION}

This remote experimentation apparatus is being tested in order to be available to students in the upcoming school year. It will then be tested and validated under different learning scenarios. These tests will provide reports of working time, number of failures, recovery from failures, maintenance average time and will give MTBF (mean time between failures) and MTTR (mean time to repair) indices. From the server database, we will get users statistics, scheduler usage, system's idle time and user waiting time, amongst others. The learning gains will also be measured against the correlation among students' autonomous usage and students' performance on exam questions related to the same topic.

\section{REFERENCES}

[1] Alves, G. R.; Marques, M. A.; Viegas, C.; Lobo, M. C.; Barral, R. G.; Couto, R. J.; Jacob, F. L.; Ramos, C. A.; Vilão, G. M.; Covita, D. S.; Alves, J.; Guimarães, P. S.; Gustavsson, I.; (2011). Using VISIR in a large undergraduate course: Preliminary assessment results. International Journal of Engineering Pedagogy, 1 (1), pp. 12-19. ISSN: 2192-4880).

[2] Costa Lobo, M. C., Alves, G. R., Marques, M. A., Viegas, C., Barral, R. G., Couto, R. J., Jacob, F. L., Ramos, C. A., Vilão, G. M., Covita, D. S., Alves, J., Guimarães, P. S., Gustavsson, I., (2011).Using remote experimentation in a large undergraduate course: initial findings. In Proceedings 41st ASEE/IEEE Frontiers in Education Conference (FIE 2011), ISBN: 978-1-61284-467-1. (12-15 October 2011)

[3] Nuno Sousa, Gustavo R. Alves, and Manuel G. Gericota, “An Integrated Reusable Remote Laboratory to Complement Electronics Teaching”, IEEE Transactions on Learning Technologies, July-Sept. 2010, Vol. 3, nr. 3, pp. 265 - 271, ISSN: 1939-1382

[4] Martin Connors, Christy Bredeson, Farook Al-Shamali,Distance Education Introductory Physics Labs: Online or In-Home?, chapter 15 in Using Remote Labs in Education, edited by Javier Garcia Zubía and Gustavo R. Alves, University of Deusto Press, ISBN: 978-84-9830-335-3, December 2011

\section{AUTHORS}

Carlos Paiva, Pedro Nogueira, Gustavo Alves, Arcelina Marques, Pedro Guimarães and Rubem Couto are with the Polytechnic of Porto - School of Engineering, R. Dr. António Bernardino de Almeida, 431, 4200-072 Porto, Portugal (e-mail: \{cmolp, pmcno, gca, mmr, psg, prtc\}@ isep.ipp.pt).

This work was supported by ISEP through internal funds.It is an extended and modified version of a paper presented at the International Conference on Remote Engineering \& Virtual Instrumentation (REV2012), held at University of Deusto, Bilbao, Spain, July 4-6, 2012. Received 26 September 2012. Published as resubmitted by the authors 18 December 2012 